\title{
Capitate-trapezoid synostosis: analysis of an Early Bronze Age case and review of the literature
}

\author{
P. Saccheri ${ }^{1}$, G. Sabbadini ${ }^{2}$, E. Crivellato ${ }^{1}$, A. Canci ${ }^{3}$, F. Toso ${ }^{4}$, L. Travan ${ }^{1}$ \\ ${ }^{1}$ Department of Experimental and Clinical Medicine, Section of Anatomy, University of Udine, Italy \\ ${ }^{2}$ Department of Medical, Surgical and Health Sciences, University of Trieste, Italy \\ ${ }^{3}$ Department of History and Preservation of the Cultural Heritage, University of Udine, Italy \\ ${ }^{4}$ Department of Diagnostic Imaging, University Hospital of Udine, Italy \\ [Received: 22 July 2016; Accepted: 2 September 2016]
}

Background: Carpal synostoses are congenital defects characterised by complete or incomplete coalition of two or more carpal bones. Although most of these defects are discovered only incidentally, sometimes they become clinically manifest. Among the different types of carpal coalition, the synostosis between capitate and trapezoid bones is quite rare, with only sparse data available in the literature. The aim of this report was to describe a case of capitate-trapezoid synostosis (CTS) observed in an ancient human skeleton, as well as to scrutinise the pertinent literature in order to assess for the characteristics of this type of defect, including its potential relevance to clinical practice.

Materials and methods: We studied the skeletal remains of an Early Bronze Age male warrior affected by incomplete CTS. Macroscopic and radiological examination of the defect was carried out. We also performed a comprehensive PubMed search in the Medline and other specialty literature databases to retrieve and analyse data relevant to the subject under consideration.

Results and Conclusions: The present case is the most ancient CTS ever found. In those literature-reported cases accompanied by careful anatomical description, such as the present one, incomplete coalition invariably occurs between the dorsal surfaces of the two bones, this characteristic emerging as a distinctive morphological trait. Literature analysis further suggests that the true prevalence of CTS is likely to be higher than estimates based on data gathered from radiology series, and that this defect may be associated with pain and carpal bossing more frequently than generally thought. (Folia Morphol 2017; 76, 2: 149-156)

Key words: capitate-trapezoid fusion/coalition, carpal fusion/coalition/ /synostosis, anthropology

\section{INTRODUCTION}

Carpal coalitions (CCs) are congenital defects in which two or more carpal bones are partially or entirely merged. According with Cockshott [12], the term carpal "fusion" should be restricted to acquired conditions. In these cases, carpal bones are originally separated and fasten together as the consequence of trauma or the result of different pathological condi- tions, such as rheumatoid, juvenile or psoriatic arthritis, and Reiter's syndrome [42]. Instead, the terms carpal coalition or "synostosis" refer to the congenital forms. Here, a developmental failure occurs between the $4^{\text {th }}$ to $8^{\text {th }}$ week of embryonic life at the site of the future joint space, followed by chondrification of the articular interzone that causes lack of separation of two or more carpal bones $[12,19]$. The true preva- 
lence of CC in the general population is not well defined and estimates vary considerably across different ethnic groups [7, 14, 39, 42]. In the vast majority of cases, CC represents an isolated, often asymptomatic, defect involving two adjacent bone elements of the same carpal row. Multiple coalitions affecting bones positioned at different rows are rarer and frequently associated with additional developmental defects in the context of complex clinical syndromes [8].

Nearly all possible combinations of CC have been described. The most common situation implicates lunate and triquetral coalition, followed by the joining of capitate and hamate bones [14, 39, 42]. In contrast, capitate-trapezoid synostosis (CTS) is assumed to be quite rare [14, 39, 42], only a few cases having been reported in the literature. Notably, a complete overview of such sparse data is missing.

The purpose of this article is to depict a case of CTS observed in the skeletal remains of a male dug up from an Early Bronze Age tumulus grave located in Northeastern Italy, and to perform a systematic review of the current literature to better define the prevalence, morphological characteristics and clinical significance of this type of coalition.

\section{CASE REPORT}

In 1980, near Selvis di Remanzacco, a village located in the Northeastern region of Italy, archaeologists uncovered the tumulus grave of a young man (20-25 years at death), buried with a dagger [44]. ${ }^{14} \mathrm{C}$ dating of the skeletal remains, performed by CEDAD laboratories, University of Salento, revealed a date between 1980 and 1730 BC (Early Bronze Age). The characteristics of the grave and the dagger denoted the high social status of the individual, probably a young but eminent member of a warrior caste [44]. By re-examining this skeleton several years later, we were able to observe the previously unnoticed synostosis of the left capitate and the trapezoid. On the dorsal surface, this synostosis was complete. On the palmar face, the two bones were separated by a groove (Figs. 1, 2). Articular facets opposite to the contiguous bones were present and normal shaped. $X$-ray examination revealed a regular spongy bone texture of the capitate-trapezoid complex, with a continuous trabecular network spanning from capitate to trapezoid. This feature was confirmed by digital tomosynthetic acquisition (Figs. 3, 4). The other left carpal and metacarpal bones were present and normally shaped. In the right hand, the capitate was

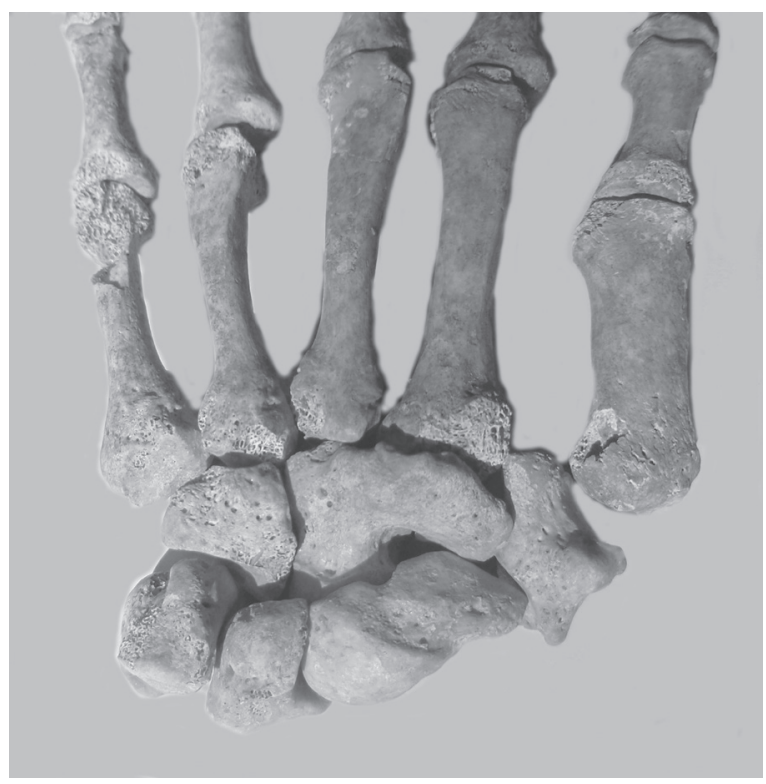

Figure 1. Left wrist, dorsal view. The capitate-trapezoid complex is well appreciable. The synostosis between the two bones is complete.

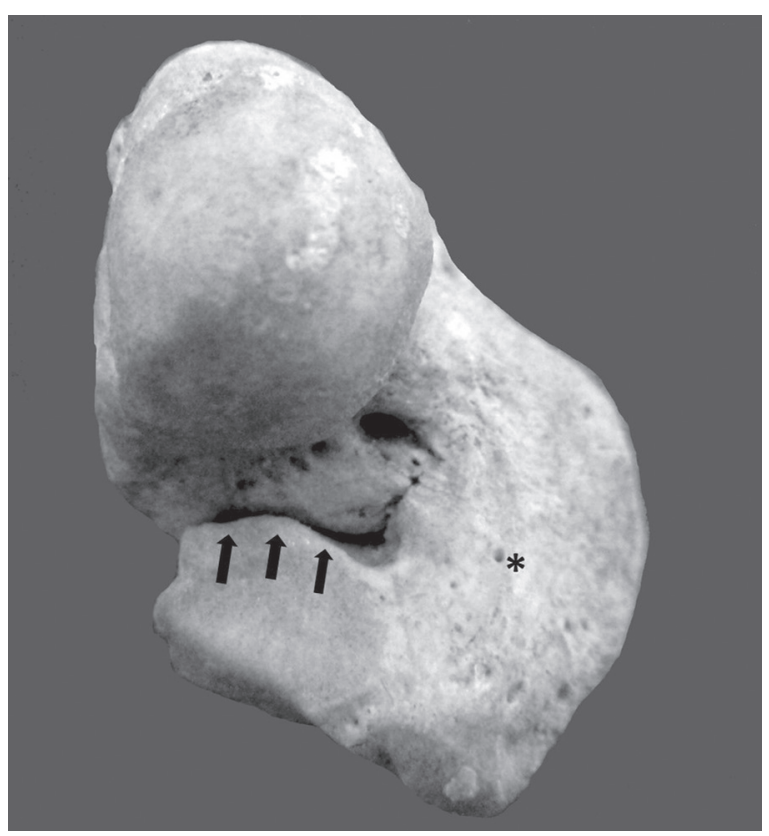

Figure 2. The capitate-trapezoid complex. A thin groove divides the palmar surface of the two bones (arrows). The dorsal surface is completely merged (asterisk).

missing but the trapezoid was present and exhibited its ordinary configuration. Examination of the rest of the skeleton was unremarkable. Cause of death could not been determined. 


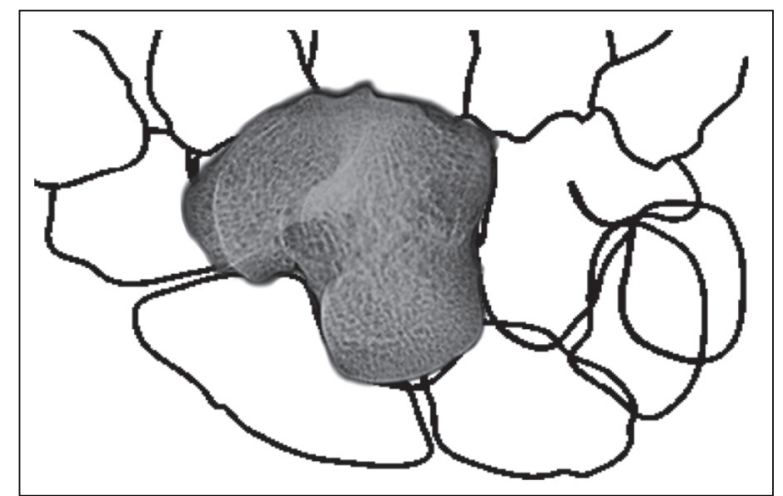

Figure 3. X-ray of capitate-trapezoid synostosis overlapped with carpal anatomy drawing.

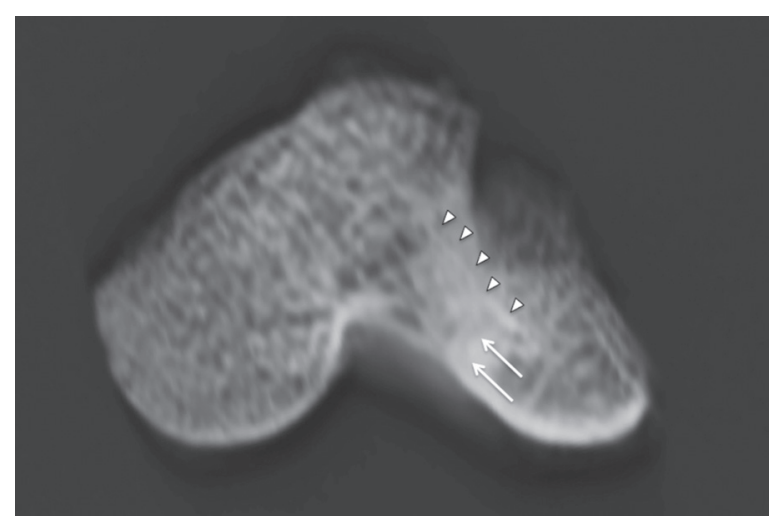

Figure 4. X-ray tomosynthetic imaging of capitate-trapezoid synostosis. Arrowheads indicate one uninterrupted trabecula crossing the two bones; arrows indicate the incomplete groove, visible on the palmar face.

\section{LITERATURE REVIEW}

The chance detection of the here reported Bronze Age CTS sample prompted us to further investigate on this subject. To this aim, a PubMed literature survey was performed on July 2016 using the following search terms: "capitate-trapezoid coalition/synostosis/fusion" and "carpal coalition/synostosis/fusion". No time restriction for publication dates was used. Case series and reports, editorials, and reviews were included. To ensure that no studies were missed, the cited references in the relevant studies were also reviewed. In addition to the pertinent literature identified from the Medline database, some of the articles were retrieved through interlibrary loans by the University of Udine Medical School Library. Further information relevant to the subject of the present study was obtained from radiology sites available on the Internet. Based on this literature search, we identified 28 published reports (Table 1).

\section{DISCUSSION}

Carpal coalitions are well-acknowledged anatomical variants, which have been reported in nearly every possible combination. The most frequent pattern recorded in the literature is the lunate-triquetral synostosis [14, 39, 42]. From a paleopathological perspective, the most ancient case of synostosis of carpal bones, namely a lunate-triquetral coalition, was found in a Neanderthal individual dated at 74.000 to 68.000 years BP [32]. In contrast, CTS has a very uncommon occurrence [14, 39, 42], with only sparse data available in the literature. Of note, a systematic review of the existing literature on CTS is currently lacking. To the best of our knowledge, the case here described is the most ancient CTS ever found in a modern Homo sapiens. The modern literature on CTS goes back to 1883, when Anderson [3] provided the first account of this type of anomaly. At first glance, literature records appear rather heterogeneous. Some CTS descriptions refer to individuals, others to dissected wrists. Some cases were noticed as incidental findings, e.g., by sampling isolated bones, or during autopsy or observation of radiographic images (Fig. 5). Disappointingly, in several studies the number and sex of affected individuals, as well as the affected side and the frequency of bilateral forms are not specified. Clinical correlates are rarely reported as well. Thus, many of the previously published cases are poorly documented. As a matter of fact, little can be drown about the general characteristics of this type of synostosis. Being the sample too small to allow conclusive data, a descriptive summary of demographic, anatomical and clinical characteristics of the CTS population is presented in Table 2 .

\section{Demographic characteristics}

Although in the Caucasian population the reported prevalence of $0.1 \%$ is routinely accepted as the best approximation $[7,12,14]$, the true frequency of $\mathrm{CC}$ in the general population is largely unknown as many cases are asymptomatic and often remain undiagnosed. The most common type is lunate-triquetral synostosis, which accounts for around $90 \%$ of all cases in adults [14] and $69.2 \%$ of all cases in the paediatric population [39]. CTS is assumed to be one of the rarest but reported prevalence estimates vary widely. According to radiographic series, CTS 
Table 1. Identified cases of capitate-trapezoid synostosis

\begin{tabular}{|c|c|c|c|c|c|c|c|}
\hline $\begin{array}{l}\text { First author, year } \\
\text { [reference] }\end{array}$ & $\begin{array}{l}\text { No. of } \\
\text { cases }\end{array}$ & Material & Sex & $\begin{array}{l}\text { Ancestry/ } \\
\text { /geography }\end{array}$ & $\begin{array}{l}\text { Side of } \\
\text { coalition }\end{array}$ & $\begin{array}{l}\text { Type of } \\
\text { coalition }\end{array}$ & Symptoms/associated anomalies \\
\hline Anderson, 1883 [3] & 1 & Bone & NA & European $^{\mathrm{a}}$ & Right* & Incomplete & NA \\
\hline Cave, 1926 [9] & 1 & Cadaver & Male & European $^{\mathrm{a}}$ & Bilateral & Incomplete & $\begin{array}{l}\text { Fusion of the styloid } \\
\text { process of III metacarpal } \\
\text { with the CT complex }\end{array}$ \\
\hline Bogart, 1932 [4] & 2 & Radiologic images & NA & NA & NA & NA & NA \\
\hline \multirow[t]{2}{*}{ Lönnerblad, 1935 [28] } & 1 & Radiologic images & Male & European $^{\mathrm{a}}$ & Bilateral & Right: complete & Carpal bossing; pain \\
\hline & & & & & & Left: Incomplete & \\
\hline Goldstein, 1948 [21] & 1 & Radiologic images & Female & Jewish & Bilateral & Incomplete & $\begin{array}{l}\text { On the left, metastyloid } \\
\text { bone; pain }\end{array}$ \\
\hline Neiss, 1955 [31] & 1 & Radiologic images & Female & European ${ }^{\mathrm{a}}$ & Bilateral & Complete & None \\
\hline Hughes, 1966 [24] & 1 & Radiologic images & Male & European $^{\mathrm{a}}$ & Left & Complete & None \\
\hline Hanley, 1967 [23] & 1 & Radiologic images & Male & Caucasian & Left & NA & $\begin{array}{l}\text { Multiple anomalies of the } \\
\text { skeleton and other systems }\end{array}$ \\
\hline \multirow[t]{2}{*}{ Buysch, 1971 [6] } & 2 & Radiologic images & Female & European $^{\mathrm{a}}$ & Bilateral & NA & None \\
\hline & & & Female & European ${ }^{a}$ & Left & NA & None \\
\hline Garn, 1976 [18] & 1 & Radiologic images & NA & NA & NA & NA & None \\
\hline Andersen, 1979 [2] & 1 & Radiologic images & Female & European ${ }^{\mathrm{a}}$ & Bilateral & NA & $\begin{array}{l}\text { Turner syndrome; shortening } \\
\text { of the IV metacarpal }\end{array}$ \\
\hline Macnicol, 1982 [29] & 1 & Radiologic images & Female & European $^{\mathrm{a}}$ & Bilateral & NA & Kienböck disease \\
\hline Geutjens, 1994 [20] & 1 & Radiologic images & Male & Asiatic & Right & Incomplete & Carpal bossing; pain \\
\hline Peyton, 1994 [37] & 1 & Radiologic images & Male & Caucasian & Bilateral & NA & Fracture; pain; bilateral club feet \\
\hline Choudhry, 1998 [10] & 1 & Bone & Male & Indian $^{b}$ & Left & Incomplete & $\begin{array}{l}\text { Absence of the styloid process } \\
\text { of III metacarpal; carpal bossing }\end{array}$ \\
\hline Parlorio, 2003 [35] & 1 & Radiologic images & Male & NA & NA & NA & NA \\
\hline Huntley, 2007 [25] & 1 & Radiologic images & Male & NA & Bilateral & Incomplete & $\begin{array}{l}\text { Bilateral trapezoid hypoplasia } \\
\text { Bilateral ulnar plus variation }\end{array}$ \\
\hline Walia, 2006 [45] & 1 & Radiologic images & Male & Indian ${ }^{b}$ & Bilateral & NA & Sharp pain during sport activity \\
\hline Alemohammad, 2009 [1] & 5 & Cadaver & NA & NA & NA & Incomplete & Carpal bossing \\
\hline Kennedy, 2010 [26] & 1 & Radiologic images & Male & Caucasian & Left $^{*}$ & NA & $\begin{array}{c}\text { Synostosis between the left lunate } \\
\text { and triquetrum }\end{array}$ \\
\hline Peters, 2011 [36] & 1 & Radiologic images & Male & European $^{\mathrm{a}}$ & Left & Incomplete & $\begin{array}{l}\text { Pain during sport activity; } \\
\text { bone marrow oedema }\end{array}$ \\
\hline Schubert, 2011 [41] & 1 & Radiologic images & Female & Caucasian & NA & Incomplete & NA \\
\hline \multirow[t]{2}{*}{ DeFazio, 2013 [14] } & 2 & Radiologic images & NA & NA & Right* $^{*}$ & NA & None \\
\hline & & & Female & Haitian & Bilateral & NA & None \\
\hline Spaans, 2013 [43] & 1 & Radiologic images & Female & European $^{\mathrm{a}}$ & Left $^{*}$ & NA & Pain; bone marrow oedema \\
\hline Pope, 2014 [38] & 1 & Radiologic images & Female & NA & Left $^{*}$ & Incomplete & $\begin{array}{l}\text { Pain; abnormality of the triangular } \\
\text { fibrocartilage complex }\end{array}$ \\
\hline \multirow[t]{4}{*}{ Mespreuve, 2015 [30] } & 4 & Radiologic images & Female & European ${ }^{\mathrm{a}}$ & NA & $\begin{array}{l}\text { Fibrocartilaginous } \\
\text { coalition }\end{array}$ & $\begin{array}{l}\text { Pain; bone marrow oedema; } \\
\text { subchondral cysts }\end{array}$ \\
\hline & & & Male & European $^{\mathrm{a}}$ & NA & Complete & None \\
\hline & & & Female & European ${ }^{\mathrm{a}}$ & NA & Incomplete & None \\
\hline & & & Male & European ${ }^{\mathrm{a}}$ & NA & NA & Capitate-hamate coalition \\
\hline Christ, 2016 [11] & 1 & Radiologic images & Male & NA & Bilateral & Complete & $\begin{array}{l}\text { Right scapholunate } \\
\text { ligament tear }\end{array}$ \\
\hline Pruszczynski, 2016 [39] & & Radiologic images & NA & NA & NA & NA & None \\
\hline Present case & 1 & Bone & Male & Caucasian & Left & Incomplete & NA \\
\hline
\end{tabular}

NA — not available; CT complex — capitate-trapezoid complex; anspecified but in all probability Caucasian; ${ }^{b}$ Unspecified but in all probability Asiatic; ${ }^{*}$ Contralateral wrist not available 
Boston Forninn Transtript ${ }_{E}^{\text {last }}$

WRIST AND ANKLE

The Clinical Significance of Variations of Bones Set Forth by Pznfessor Dwight

"The Clinical Sisnificance of variations of Wrist and Ankle" was the subject of a paper by Professor Thomas Dwight, head of the anatomleal department of the Harvard Medical Sohool, read at this afternoon's session of the section which was held in Huntington Hall.

The paper was a statement of varlations of bones of the wrist and ankle, whicn the author has invesugated for years. It contained little that was new to professional anatomists, but was intended to call the attention of surgeons to the practical application of these observations. The $X$-ray shows many curious conditions which formerly were never presented to the sturgeon: and Professor Dwight sald It is Important to know that certain variattons from the normal arrangement of the bones is not the result of an injury or of disease, but is due to a congenital vartation.

These pecullaritles may be divided into four classes: The flrst is due to an increase in the number of bones owing to the persistence of elements which normally fuse or disappear: the second to a diminution of bones owing to the union of elements usually distinct; the third to unusual relatlons betwcen bones: and the fourth to the exceptional development of elements usually small or absent. It follows from this that to whlchever class the variation may belong there are certain places in the wrist or ankle in which it may be expected to be found in a certain per cent of cases. and that when it does occur it is to be recornized as non-pathological. It was not dented that pathological condlitons mas sometimes accompany these variatlons or even be caused by them, thus making the diagnosis aimcult. It is probable, for Instance, that most of the cases of so-called fracture of the scaphold bone of the Nriat are really separations of the two chlef parts of the bone which have not fused as they usually do in the course of development.

The paper was illustrated by nearly thirty stereopticon views, which. with one exception, mere from photographs of Professor Dwight's own observations.

Figure 5. This article, published in 1906 on the Boston Evening Transcript, illustrates the pioneering X-ray investigation of Thomas Dwight, anatomy professor at Harvard, on the congenital variations in wrist and ankle [17].

seems to be uncommon $(0.005-0.1 \%)[4,24,39]$; by contrast, Alemohammad et al. [1] found 5 cases of CTS $(2.4 \%)$ in 202 dissected wrists. Thus, CTS preva-
Table 2. Descriptive characteristics of capitate-trapezoid synostosis (CTS) population

\begin{tabular}{|c|c|c|}
\hline Characteristic & Values & $\mathbf{N}^{*}$ \\
\hline \multicolumn{3}{|l|}{ Prevalence rate: } \\
\hline X-ray examination [\%] & $0.005^{\wedge}-0.1^{\circ}$ & \\
\hline Cadaver examination [\%] & $2.4^{\infty}$ & \\
\hline Sex: & & 28 \\
\hline Male & $16(57.1 \%)$ & \\
\hline Female & $12(42.9 \%)$ & \\
\hline Ethnic group: & & 8 \\
\hline Caucasian & $5(62.5 \%)$ & \\
\hline Haitian & $1(12.5 \%)$ & \\
\hline Asiatic & $1(12.5 \%)$ & \\
\hline Jewish & $1(12.5 \%)$ & \\
\hline Affected side: & & $19^{\mathrm{a}}$ \\
\hline Right & $1(5.3 \%)$ & \\
\hline Left & $6(31.6 \%)$ & \\
\hline Bilateral & $12(63.1 \%)$ & \\
\hline Lesion type: & & $24^{b}$ \\
\hline Complete & $7(29.1 \%)$ & \\
\hline Incomplete & $16(66.7 \%)$ & \\
\hline Fibrocartilaginous coalition & $1(4.1 \%)$ & \\
\hline Symptoms: & & 29 \\
\hline Pain & $9(31 \%)$ & \\
\hline Carpal bossing & $3(10.3 \%)^{c}$ & \\
\hline Associated anomalies & $12(41.4 \%)$ & \\
\hline No symptoms & $10(34.5 \%)$ & \\
\hline
\end{tabular}

*Number evaluable individuals; ^ Data from reference no. [39]; ${ }^{\circ}$ Data from reference no. [4]; ${ }^{\infty}$ Data from reference no. [1]; andividuals in which both wrists were available; b ${ }^{\mathrm{N}}$ Number of wrists; ' Calculation does not include the study performed by Alemohammad et al. [1] because these authors have elaborated their data by referring the number of capitatetrapezoid synostosis cases to the number of wrists and not of individuals

lence shows different figures when it was looked for on radiographs or evaluated by wrist dissection. This inconsistency suggests that CTS may be less rare than is generally thought and that many cases may remain unappreciated on wrist radiographs.

Some reports point to a link between $\mathrm{CC}$ and ethnicity, with reported rates of $0.1-0.24 \%$ in Caucasian people, $1.6 \%$ in African Americans and 9.5\% in certain West African tribes [12-15, 19, 24, 42]. In DeFazio's et al. [14] series, which collected various types of CC in a multi-ethnic North American population, $1.2 \%$ of patients were of Caucasian descendent, $15.3 \%$ non-black Hispanic and $83.5 \%$ of Afro-Caribbean descendent [14]. In Pruszczynski's et al. [39] 
Table 3. deVilliers Minnaar, Singh and Burnett classifications of carpal coalitions

\begin{tabular}{|c|c|c|c|}
\hline First author [reference] & Classification scheme & & \\
\hline \multirow[t]{4}{*}{ deVilliers Minnaar [16] } & Type I & & Pseudoarthrosis \\
\hline & Type ॥ & & Synostosis with a notch \\
\hline & Type III & & Complete synostosis \\
\hline & Type IV & & Complete synostosis and other carpal anomalies \\
\hline \multirow[t]{11}{*}{ Singh [42] } & \multirow{2}{*}{$\begin{array}{l}\text { Shape of the synostosed } \\
\text { bones }\end{array}$} & Type la & Retaining shape \\
\hline & & Type Ib & Distorted shape \\
\hline & \multirow[t]{7}{*}{ Site of coalition } & Type II a & Palmar \\
\hline & & Type Il b & Dorsal \\
\hline & & Type II c & Central \\
\hline & & Type Il d & Proximal \\
\hline & & Type II e & Distal \\
\hline & & Type Il f & Intermediate \\
\hline & & Type II g & Complete \\
\hline & \multirow[t]{2}{*}{ Type of coalition } & Type III & $\begin{array}{l}\text { Apparent (the bones seem completely merged but a central cavity is } \\
\text { appreciable radiologically) }\end{array}$ \\
\hline & & Type IV & Non-osseous coalitions \\
\hline \multirow[t]{2}{*}{ Burnett [5] } & \multirow[t]{2}{*}{ Type of coalition } & \multicolumn{2}{|c|}{ Osseous synostosis } \\
\hline & & \multicolumn{2}{|c|}{ Non-osseous synostosis (syndesmosis or synchondrosis) } \\
\hline
\end{tabular}

series, which collected various types of CC in a multiethnic North American paediatric population, 32.7\% of patients self-identified as Caucasian, $59.6 \%$ as AfroAmerican, $1.9 \%$ as non-black Hispanic and $1 \%$ as Asiatic [39]. In contrast, most cases of CTS reported in the literature are Europeans, but ancestry has definitely been documented only in a minority of cases. In fact, we have found references to a specific ethnic group only in 8 published studies, including the one presented here. Five cases referred to individuals of Caucasian ancestry $[23,26,37,41]$, one case was of Asiatic origin [20], one of Haitian ancestry [14] and one Jewish [21].

Data on sex distribution in CC are conflicting, with some studies showing a higher prevalence in men [14, 33, 39] and others in women [19, 42]. With regard to CTS, gender information is based on a very few number of cases (Table 1) [2, 6, 9-11, 14, 20, 21, 23-26, 28-31, 35-38, 41, 43, 45]. When CTS cases included in our analysis are pooled together, sex appears to be determined in only 28 individuals, with a prevalence in men (Table 2 ).

\section{Anatomical characteristics}

A universally accepted classification of CC, including CTS, is lacking. In 1952, deVilliers Minnaar [16] catalogued four types of lunate-triquetral synostosis. Next, this scheme was extended to all types of CC and extensively applied. In 2003, Singh et al. [42] proposed a more detailed four-type classification system based on shape, site and characteristics of merged bones. Lately, Burnett [5] differentiated two primary forms: a) the osseous synostosis, in which the bones form a single block; and b) the non-osseous synostosis, in which the connection is produced by fibrous tissue (syndesmosis) or cartilage (synchondrosis) (Table 3).

The present review analysis reveals that incomplete coalition is the most common type of CTS. In $16(66.7 \%)$ out of 24 cases, capitate and trapezoid bones are joined to each other only partially (Table 1 ). Noteworthy, in all cases supported by a detailed structural description, the dorsal surfaces are merged. Hence, dorsal coalition seems to be as a distinctive trait of CTS. In one case, a non-osseous coalition has been documented [30].

Literature data on CC as a whole show that bilateral forms have a higher occurrence [15, 42]. Similarly, also CTS appears to be frequently bilateral (12 out of 19 cases in which both wrists have been examined, $63.1 \%$ ) with a higher occurrence on the left side when 
the condition is unilateral (Table 2$)[2,6,9-11,14$, $20,21,23-25,28,29,31,36,37,45]$.

\section{Clinical characteristics}

Usually, CCs are completely asymptomatic [14] and most of these defects are discovered as incidental findings during imaging procedures performed for other reasons. However, in a minority of cases they cause symptoms that may mimic other disease processes that may confound interpretation of imaging data $[8,40,43]$. Pain may occasionally occur, in particular as a result of sport activities requiring intense wrist movements [27, 36, 42, 45]. A compensatory increase of motion in surrounding bones, followed by consequent degenerative arthritis, has been postulated to explain this symptom [22, 27]. Incomplete CCs are more likely to cause symptoms $[11,33]$. Overcoming the widely held belief that CTS is almost always asymptomatic, our careful scrutiny of literature data reveals that this defect may be associated with wrist pain in nearly one-third of the cases (Table 2) [20, 21, 28, 30, 36-38, 43, 45]. Remarkably, pain seems to be associated with incomplete or fibrocartilaginous forms $[21,20,28,30,36$, 38]. Therefore, computed tomography or magnetic resonance imaging are required to better define the nature of coalition in symptomatic cases in order to choose the most appropriate treatment for each patient $[11,14,36]$.

From our reviewing analysis, it emerges that the association between CTS and carpal bossing, defined as "an overgrowth of bone in response of stress" [20], has been identified in 3 (10.3\%) out of 29 subjects (Table 2 ) $[10,20,28]$. This estimate does not include the study performed by Alemohammad et al. [1], who found 5 CTS out of 39 wrists affected by carpal bossing. As these figures are not comparable with the other data of our reviewing analysis, in so far as wrist reference corresponds to an indeterminate number of subjects, we excluded them by our calculation. Carpal bossing may result by the fusion of the styloid process of the III metacarpal with the capitate-trapezoid complex. This event is not uncommon. In normal wrists, variations of the styloid apophysis of the III metacarpal are frequent. Indeed, it may either grow as an isolated bone (forming the so called "os styloideum" in $2 \%$ of cases), or undergo fusion with the capitate or the trapezoid (in 3.5\% and $0.5 \%$ of cases, respectively) $[33,34]$.

At times, CTS exhibits unusual presentation or appears associated with distinct bone anomalies. Of special interest is the case published by Macnicol [29] of the remarkable association of bilateral CTS with Kienböck's disease of the lunate in the non-dominant wrist. He hypothesized that an increased stress of the lunate bone resulted in ostemalacia. Finally, we wish to mention the association between CTS and lunatetriquetral synostosis, which has been documented by Kennedy et al. [26].

\section{CONCLUSIONS}

The present analysis is the first to compile systematically the available published evidence on CTS. According to our review, this defect seems to be less rare than generally assumed. In the vast majority of cases, CTS is incomplete and bilateral; coalition of the dorsal surfaces of the two bones is a distinctive morphological trait of incomplete forms. CTS is usually asymptomatic and often discovered as an incidental finding; however, a non-negligible proportion of patients may present with pain or carpal bossing. These patients can be treated either medically or surgically, a decision that needs to be made on a case-by-case basis.

For those interested in the area of paleopathology, it is worth mentioning that the case here described represents, to the best of our knowledge, the most ancient example of CTS reported in the literature. We believe that any research finding, as this case is, that helps sparking renewed interest in revisiting a topic should not be considered a mere academic curiosity.

\section{Acknowledgements}

The authors are grateful to the Superintendence for the Archaeological Heritage of Friuli Venezia Giulia for providing access to skeletal material. This work was supported by local funds from Ministero dell'Istruzione, dell'Università e della Ricerca, Rome, to the Department of Experimental and Clinical Medicine, Section of Human Anatomy, University of Udine, Italy.

\section{REFERENCES}

1. Alemohammad AM, Nakamura K, El-Sheneway M, et al. Incidence of carpal boss and osseous coalition: an anatomic study. J Hand Surg Am. 2009; 34(1): 1-6, doi: 10.1016/j. jhsa.2008.08.025, indexed in Pubmed: 19081681.

2. Andersen Jr. PE, Schwartz W. Doppelseitige Synostosen zwischen dem Os trapezoideum und dem Os capitatum bei Turner-Syndrom. Radiologe. 1979; 19: 499-501.

3. Anderson RJ. Division of the scaphoid bone of the carpus, with notes on other varieties of the carpal bones. J Anat Physiol. 1883; 17: 253-255, indexed in Pubmed: 17231472. 
4. Bogart FB. Variations of the bones of the wrist. Am J Roentgenol Radium Ther. 1932; 28: 638-646.

5. Burnett SE. Hamate-pisiform coalition: morphology, clinical significance, and a simplified classification scheme for carpal coalition. Clin Anat. 2011; 24(2): 188-196, doi: 10.1002/ca.21086, indexed in Pubmed: 21322040.

6. Buysch K, Drewes J, Günther D. Synostosen zwischen Multangulum minus und Capitatum. Fortschr Röntgenstr. 1971; 115(08): 267-268.

7. Carlson DH. Coalition of the carpal bones. Skeletal Radiol. 1981; 7(2): 125-127, indexed in Pubmed: 7330662.

8. Castriota-Scanderbeg A, Dallapiccola B Abnormal skeletal phenotypes. Springer-Verlag, Berlin Heidelberg 2005: 434.

9. Cave AJ. Fusion of carpal elements. J Anat. 1926; 60(Pt 4): 460-461, indexed in Pubmed: 17104118.

10. Choudhry R, Tuli A, Chimmalgi M, et al. Os capitatotrapezoid: a case report. Surg Radiol Anat. 1998; 20(5): 373-375, indexed in Pubmed: 9894320.

11. Christ AB, Maertens AS, Weiland AJ. Bilateral Complete Osseous Coalition of the Capitate and Trapezoid. J Wrist Surg. 2016; 5(3): 233-235, doi: 10.1055/s-0036-1579548, indexed in Pubmed: 27468375.

12. Cockshott WP. Carpal fusions. Am J Roentgenol Radium Ther Nucl Med. 1963; 89: 1260-1271, indexed in Pubmed: 14021907.

13. Cockshott WP. Pisiform hamate fusion. J Bone Joint Surg Am. 1969; 51(4): 778-780, indexed in Pubmed: 5783858.

14. DeFazio M, Cousins B, Miversuski R, et al. Carpal coalition. A review of current knowledge and report of a single institution's experience with asymptomatic intercarpal fusion. HAND. 2013; 8(2): 157-163, doi: 10.1007/s11552013-9498-5.

15. Delaney TJ, Eswar S. Carpal coalitions. J Hand Surg Am. 1992; 17(1): 28-31, indexed in Pubmed: 1538108.

16. deVilliers Minnaar AB. Congenital fusion of the lunate and triquetral bones in the South African Bantu. J Bone Joint Surg Br. 1952; 34-B(1): 45-48, indexed in Pubmed: 12999869.

17. Dwight T. Variations of bones of hands and feet. A clinical atlas. J.B. Lippincott Ed,, Philadelphia 1907: 13.

18. Garn SM, Burdi AR, Babler WJ. Prenatal origins of carpal fusions. Am J Phys Anthropol. 1976; 45(2): 203-208, doi: 10.1002/ajpa.1330450206, indexed in Pubmed: 961836.

19. Garn SM, Frisancho AR, Poznanski AK, et al. Analysis of triquetral-lunate fusion. Am J Phys Anthropol. 1971; 34(3): 431-433, doi: 10.1002/ajpa.1330340313, indexed in Pubmed: 5120558.

20. Geutjens G. Carpal bossing with capitate-trapezoid fusion. A case report. Acta Orthop Scand. 1994; 65(1): 97-98, indexed in Pubmed: 8154295.

21. Goldstein R. Congenital synostosis of carpal and tarsal bones and ankylosis cubiti. Radiol Clin. 1948; 17(2): 66-73, indexed in Pubmed: 18859682

22. Gross S, Watson HK, Strickland J, et al. Triquetral-lunate arthritis secondary to synostosis. J Hand Surg Am. 1989; 14(1): 95-102, doi: 10.1016/0363-5023(89)90065-8.

23. Hanley WB, McKusick VA, Barranco FT. Osteochondritis dissecans with associated malformations in two brothers. A review of familial aspects. J Bone Joint Surg Am. 1967; 49(5): 925-937, indexed in Pubmed: 4382085.

24. Hughes PC, Tanner JM. The development of carpal bone fusion as seen in serial radiographs. Br J Radiol. 1966; 39(468): 943-949, doi: 10.1259/0007-1285-39-468-943, indexed in Pubmed: 5954094.

25. Huntley JS, Hooper G. Carpal anomalies. Clin Anat. 2007; 20(3): 326-328, doi: 10.1002/ca.20283, indexed in Pubmed: 16617457.

26. Kennedy K, Waller CJ, Hartley RH. Congenital lunotriquetral and capitotrapezoid coalitions. J Hand Surg Eur Vol. 2010;
35(1): 79-80, doi: 10.1177/1753193409346749, indexed in Pubmed: 20100720.

27. Knezevich S, Gottesman M. Symptomatic scapholunatotriquetral carpal coalition with fusion of the capitatometacarpal joint. Report of a case. Clin Orthop Relat Res. 1990(251): 153-156, indexed in Pubmed: 2295166.

28. Lonnerblad L. Uber Zwei Seltene Anomalien(?) Im Carpus. Acta Radiologica. 2010; 16(6): 682-690, doi: 10.3109/ 00016923509174806.

29. Macnicol MF. Kienböck's disease in association with carpal coalition. HAND. 1982; 14(2): 185-187, indexed in Pubmed: 7117935.

30. Mespreuve M, De Cuyper K, Vansevenant M, Verstraete K (2015) Carpal coalition: 4 cases of a rare bony coalition between the capitate and trapezoid bone, with MRI findings in a symptomatic case. http://www.eurorad.org/case. php?id=12910 doi: 10.1594/eurorad/case.12910 (Accessed 2015 September 08).

31. Neiss A. Doppelseitige Synostose zwischen dem Os multangulum minus und dem Os capitatum. Fortschr Röntgenstr. 2009; 82(06): 825, doi: 10.1055/s-0029-1212631.

32. Oberlin C, Sakka M. [The most ancient case of synostosis of the carpal bones: pyramido-lunate synostosis in La Ferrassie man]. Ann Chir Main. 1989; 8(3): 269-272, indexed in Pubmed: 2684063.

33. O'Rahilly R. A survey of carpal and tarsal anomalies. J Bone Joint Surg Am. 1953; 35-A(3): 626-642, indexed in Pubmed: 13069551.

34. Park MJ, Namdari S, Weiss AP. The carpal boss: review of diagnosis and treatment. J Hand Surg Am. 2008; 33(3): 446-449, doi: 10.1016/j.jhsa.2007.11.029, indexed in Pubmed: 18343306.

35. Parlorio E. Carpal coalitions. http://www.eurorad.org/case. php?id=2408 (Accessed 2016 July 08).

36. Peters S, Colaris JW. Carpal coalition: symptomatic incomplete bony coalition of the capitate and trapezoid-case report. J Hand Surg Am. 2011; 36(8): 1313-1315, doi: 10.1016/j.jhsa.2011.05.011, indexed in Pubmed: 21664766

37. Peyton RS, Moore JR. Fracture through a congenital carpal coalition. J Hand Surg Am. 1994; 19(3): 369-371, doi: 10.1016/0363-5023(94)90047-7, indexed in Pubmed: 8056960.

38. Pope T, Bloem HL, Beltran J, Morrison WB, Wilson DJ. Musculoskeletal Imaging. Elsevier Saunders, Philadelphia 2014: 1085.

39. Pruszczynski B, Saller J, Rogers KJ, et al. Incidence of carpal coalition in the pediatric population. J Pediatr Orthop. 2016; 36(8): e106-e110, doi: 10.1097/ BPO.0000000000000639, indexed in Pubmed: 26398433.

40. Rice J, Stephens M, Colville J. Scaphoid osteochondroma mimicking carpal coalition. J Hand Surg Br. 1996; 21(6): 779-780, indexed in Pubmed: 8982925.

41. Schubert R. Capitato-trapezoid synostosis. http://radiopaedia.org/ (Accessed 2016 July 08).

42. Singh $P$, Tuli $A$, Choudhry $R$, et al. Intercarpal fusion: a review. J Anat Soc India. 2003; 52: 183-188.

43. Spaans A, Beumer A. Carpal coalitions; failures of differentiation of the carpus: a description of cases. Open J Radiol. 2013; 3: 1-6, doi: 10.4236/ojrad.2013.31001.

44. Vitri S. Le prime indagini in tumuli friulani: gli scavi della Soprintendenza per i beni Archeologici del Friuli Venezia Giulia. In: Cassola Guida P, Calosi M (eds) Una sepoltura monumentale dell'antica età del Bronzo: il tumulo di Sant'Osvaldo (Udine). Scavi 2000-2002. Studi e Ricerche di Protostoria mediterranea 9. Quasar, Roma 2011: 99-104.

45. Walia J, Singh A, Walia AK, et al. Bilateral coalition of capitate and trapezoid a very rare case. Indian J Radiol Imag. 2006; 16(4): 585, doi: 10.4103/0971-3026.32275. 